\title{
PENGARUH PERBEDAAN BENTUK PENAMPANG SPESIMEN TERHADAP HUBUNGAN TEGANGAN DAN REGANGAN PADA BETON HIGH VOLUME FLY ASH SELF COMPACTING CONCRETE (HVFA-SCC)
}

The Effect of Speciment Shape on Stress-Strain Behavior of High Volume Fly ash - Self Compacting Concrete (HVFASCC)

\author{
Retno Kusuma Astuti (c), Agus Setiya Budi (b) Senot Sangadji (c) \\ ${ }^{a, b, c}$ Civil Engineering Department, Sebelas Maret University, Indonesia
}

(1)

\begin{abstract}
ABSTRAK
Penggunaan fly ash sebagai pengganti sebagian semen dalam campuran Self Compacting Concrete dengan kadar lebih dari 50\% disebut High Volume Fly Ash Self Compacting Concrete (HVFA SCC). Pengujian beton dilakukan dengan berbagai bentuk sampel sesuai dengan standar yang digunakan. Salah satu factor yang mempengaruhi hasil pengujian adalah bentuk penampang beton. Penelitian ini menggunakan total benda uji 18 buah dengan variasi bentuk penampang lingkaran, segiempat dan segienam. Rancang campur yang digunakan pada High Volume Fly Ash Self Compacting Concrete menggunakan teknologi SCC berdasar EFNARC Specification and Guidelines for Self-Compacting Concrete, 2002. Hasil dari penelitian ini menunjukkan bahwa HVFA SCC pada umur 28 hari memiliki kuat desak yang lebih rendah dibandingkan dengan beton normal dengan rata-rata penurunan kekuatannya adalah $27 \%$. Beton normal dengan penampang segiempat memiliki kuat desak terendah dengan kenaikan sebesar 23\% untuk segienam dan $41 \%$ untuk lingkaran, begitu pula dengan HVFA-SCC, penampang segiempat memiliki kuat desak terendah dengan kenaikan sebesar $43 \%$ untuk segienam dan $52 \%$ untuk lingkaran. Nilai Modulus Elastisitas rata-rata pada HVFA-SCC lebih kecil dibandingkan beton normal, yaitu 9578,47 MPa untuk HVFA-SCC dan 13774,44 MPa untuk beton normal. . Nilai toughness postcapeak rata-rata dari HVFA-SCC lebih besar dibandingkan nilai toughness postcapeak beton normal, yaitu 0,036 untuk HVFASCC dan 0,033 untuk beton normal. Begitupula dengan nilai daktilitas, yaitu 6,93 untuk HVFA-SCC dan 5,44 untuk beton normal.
\end{abstract}

Kata Kunci : HVFA-SCC, SCC, fly ash, shape effect, tegangan dan regangan

\begin{abstract}
The use of fly ash as a partial replacement of cement in a mixture of Self Compacting Concrete with levels greater than 50\% or called High Volume Fly Ash Self Compacting Concrete (HVFA SCC). In concrete quality testing, there are various formworks that are used according to different standards. This research used a total of 18 test specimens with variation of circular, square and hexagonal cross-sections, three samples for each variation of cross-section form for normal concrete and 28-day-HVFA-SCC. The mixed design used in High Volume Fly Ash Self Compacting Concrete uses SCC technology based on EFNARC Specification and Guidelines for Self-Compacting Concrete, 2002. According to the research result, it was found that HVFA SCC at 28-days had a lower compressive strength of concrete compared to normal concrete with an average decrease in strength was $27 \%$. The normal concrete with rectangular cross-section has the lowest compressive strength with an increase of 23\% for the hexagon and 41\% for the circle, as well as with HVFA-SCC, the rectangular cross-section has the lowest compressive strength with an increase of 43\% for the hexagon and 52\% for the circle. The Elasticity Modulus Value in HVFA-SCC is smaller than normal concrete, 9578,47 MPa for HVFA-SCC and 13774,44 MPa for normal concrete. The value of the pascapeak toughness of HVFA-SCC is greater than the value of normal concrete pascapeak toughness, 0,036 for HVFA-SCC and 0,033 for normal concrete. The value of HVFA-SCC ductility is higher the normal concrete 6,93 for HVFA-SCC and 5,44 for normal concrete.
\end{abstract}

Keywords: HVFA-SCC, SCC, fly ash, shape effect, stress and strain 


\section{Pendahuluan}

Penggunaan fly ash sebagai pengganti sebagian semen dalam campuran Self Compacting Concrete dengan kadar lebih dari 50\% atau disebut High Volume Fy Ash Self Compacting Concrete (HVFA SCC) akan menambah kemampuan aliran beton segar, mengurangi kapur padam aktif sebagai hasil sampingan dari proses hidrasi antara semen dan air yang cenderung melemahkan beton serta menambah kepadatan beton karena butiran fly ash akan berperan sebagai filler antar agregat. Fly Ash adalah produk sampingan terutama dari pembangkit listrik tenaga uap (PLTU) bertenaga batu bara. Fly Ash merupakan partikel yang sangat halus dengan diameter antara 1 - 150 mikron meter dan berbentuk butiran bulat. Bahan Material fly ash bersifat sebagai pozzolan. Pozzolan adalah bahan yang mengandung senyawa silika atau silica alumina dan alumina, yang tidak mempunyai sifat mengikat seperti semen akan tetapi dalam bentuk yang halus dan dengan adanya air maka senyawa - senyawa tersebut akan bereaksi dengan kalsium hidroksida $\left(\mathrm{Ca}(\mathrm{OH})_{2}\right)$ pada suhu normal membentuk senyawa kalsium silikat hidrat $\left(\mathrm{C}_{3} \mathrm{~S}_{2} \mathrm{H}_{3}\right.$ atau tubermorite). Reaksi tersebut membuat beton lebih kuat dan padat.

Pemakaian beton lebih ditujukan dalam hal tekan, oleh karena itu grafik tegangan-regangan beton merupakan acuan utama. Prosedur pengujian kuat desak beton di Indonesia dapat dilakukan dengan mengacu SNI : 03-1974-1990. Faktor-faktor yang mempengaruhi hasil uji kuat tekan beton meliputi kondisi ujung benda uji, ukuran benda uji, rasio diameter benda uji terhadap ukuran maksimum agregat, rasio panjang terhadap diameter benda uji, kondisi kelembaban, suhu benda uji, arah pembebanan terhadap arah pengecoran, laju penambahan beban pada compression testing machine, dan bentuk geometri benda uji. Di sisi lain (Neville 2002) juga menyampaikan bahwa hasil pengujian beton dapat dipengaruhi oleh beragam faktor, seperti ukuran spesimen, bentuk cetakan yang digunakan untuk pengecoran, perawatan dan tingkat aplikasi beban. Dua jenis spesimen yang umum digunakan untuk pengujian beton adalah kubus dan silinder, meskipun memiliki banyak perbedaan, keduanya digunakan secara luas. Spesimen silinder $(150 \mathrm{~mm} \times 300 \mathrm{~mm})$ banyak digunakan di Australia, Kanada, Prancis, Selandia Baru dan Amerika Serikat, sedangkan spesimen prisma segiempat $(150 \mathrm{~mm}$ dan $100 \mathrm{~mm}$ ) kebanyakan digunakan di wilayah Eropa termasuk Inggris dan Jerman. Penelitian untuk mengestimasi kurva tegangan-regangan pada beton telah banyak dilakukan oleh para peneliti, seperti yang telah dilakukan Del Viso(2007) didapatkan bahwa perilaku atau karakteristis grafik tegangan regangan beton pasca-puncak bergantung pada bentuk spesimen. Pada penelitian ini HVFA-SCC dan beton normal digunakan untuk menganalisis pengaruh perbedaan bentuk penampang spesimen terhadap hubungan tegangan dan regangan pada beton high volume fly ash self compacting concrete (bvfa-scc). Hasil yang didapatkan adalah perbandingan kuat tekan, modulus elastisitas, nilai toughness, dan nilai daktilitas. Modulus elastisitas merupakan suatu ukuran nilai yang menunjukkan kekakuan dan ketahanan beton untuk menahan deformasi (perubahan bentuk). Modulus Elastisitas dapat ditentukan dari regangan pada saat tegangan 0,4 f'c. Daktilitas adalah perbandingan antara lendutan pada saat beban ultimit dan beban saat leleh. Faktor daktilitas merupakan rasio antara simpangan ultimit dan simpangan saat terjadi leleh pertama.

\section{Metode Penelitian}

Mix Design

Proporsi material yang digunakan pada beton normal \& HVFA-SCC dapat dilihat pada tabel 1. Penelitian ini menggunakan rancang campur untuk beton normal, dan HVFA-SCC. Rancang campuran beton normal menggunakan metode SNI 03-2834-2000 (Tata Cara Pembuatan Rencana Campuran Beton Normal) untuk beton normal dan EFNARC Specification and Guidelines for Self-Compacting Concrete, 2002 untuk HVFA SCC 
Tabel 1. Mix Design HVFA-SCC

\begin{tabular}{cccccccc}
\hline Kode & $\begin{array}{c}\text { Kadar } \\
\text { Fly Ash }\end{array}$ & $\begin{array}{c}\text { Semen } \\
\left(\mathbf{k g} / \mathbf{m}^{3}\right)\end{array}$ & $\begin{array}{c}\text { Fly Ash } \\
\left(\mathbf{k g} / \mathbf{m}^{3}\right)\end{array}$ & $\begin{array}{c}\text { Kerikil } \\
\left(\mathbf{k g} / \mathbf{m}^{3}\right)\end{array}$ & $\begin{array}{c}\text { Pasir } \\
\left(\mathbf{k g} / \mathbf{m}^{3}\right)\end{array}$ & $\begin{array}{c}\text { Air } \\
\left(\mathbf{l t} / \mathbf{m}^{3}\right)\end{array}$ & $\begin{array}{c}\text { Sp } \\
\left(\mathbf{l t} / \mathbf{m}^{3}\right)\end{array}$ \\
\hline HVFA-SCC & $50 \%$ & 384.3 & 384.3 & 709.8 & 595.35 & 231 & 7.686 \\
\hline NORMAL & $0 \%$ & 750 & - & 782.42 & 566.58 & 231 & - \\
\hline
\end{tabular}

Nilai yang didapat dari uji slump beton normal segar adalah $13 \mathrm{~cm}$, sedangkan hasil pengujian slum flow pada HVFA-SCC disajikan pada Tabel 2.

Tabel 2. Slump flow HVFA-SCC

\begin{tabular}{cccc}
\hline Kode & \multicolumn{3}{c}{ Parameter } \\
\cline { 2 - 4 } & diameter & t500 (sec) & Velocity $(\mathrm{mm} / \mathrm{sec})$ \\
\hline HVFA-SCC & 750 & 3.61 & 138.5 \\
\hline
\end{tabular}

Penelitian ini menggunakan total benda uji 18 buah dengan 3 variasi bentuk penampang, yaitu lingkaran, segiempat dan segienam dengan masing-masing bentuk penampang terdiri dari 3 sampel untuk beton normal dan HVFA-SCC umur 28 hari. Curing benda uji dilakukan dengan menutup benda uji dengan kain basah dalam waktu 28 hari dan selanjutnya diuji tekan menggunakan Universal Testing Machine (UTM). Kecepatan pembebanan (load rate) pada penelitian ini didasarkan pada ASTM C-39M dengan menggunakan strain rate control sebesar $0,3 \mathrm{~mm} / \mathrm{menit}$. Hasil yang didapatkan dari UTM berupa besarnya gaya pembebanan $(\mathrm{N})$ dan besarnya deformasi $(\mathrm{mm})$. Dari hasil pengujian tekan diolah menjadi grafik tegangan dan regangan yang disajikan dalam gambar 1. 
Hasil dan Pembahasan

Hasil diagram tegangan regangan HVFA-SCC dan Beton Normal

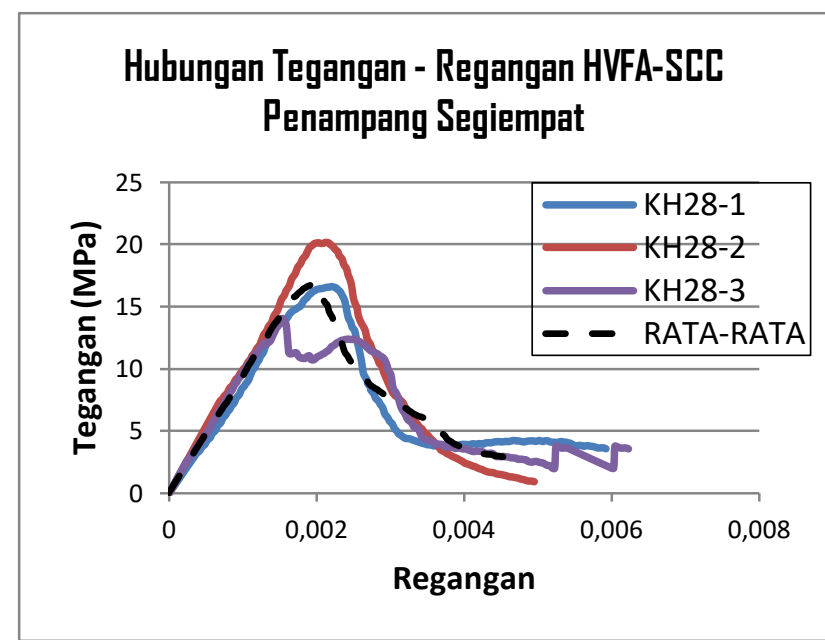

Gambar 1a

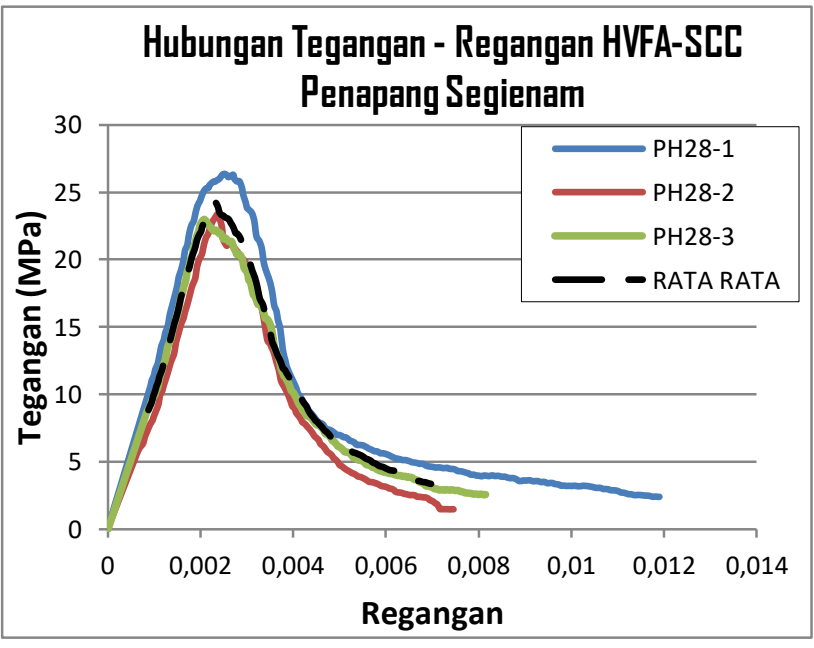

Gambar 1c

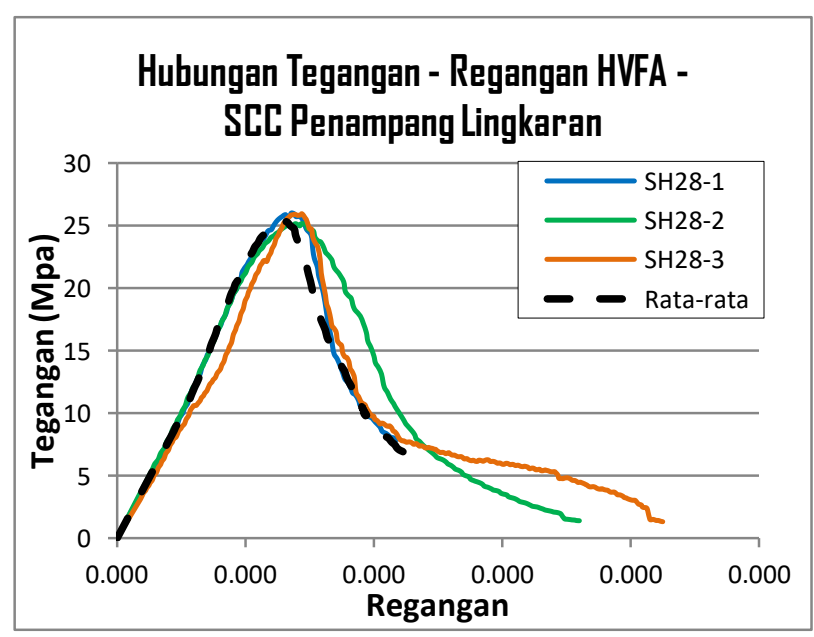

Gambar 1e

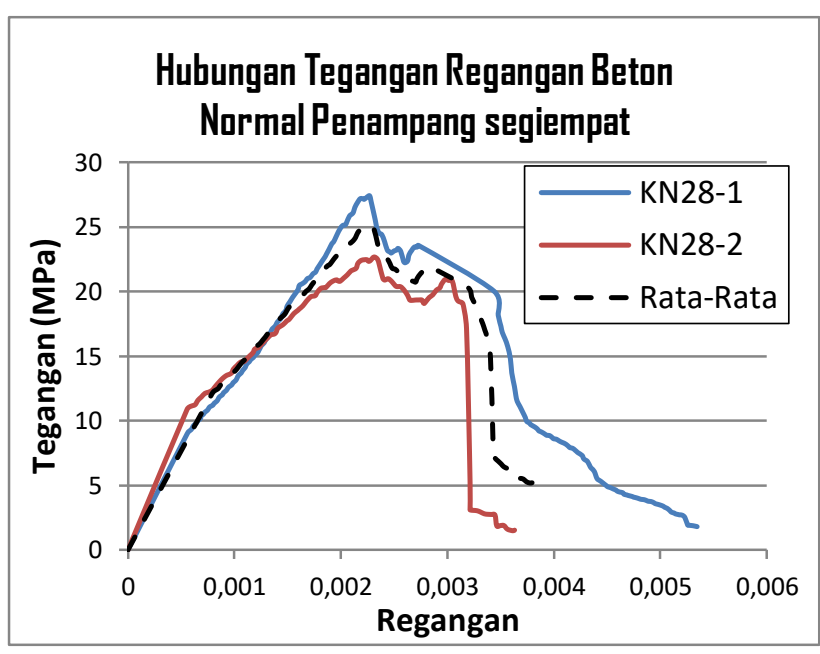

Gambar 1b

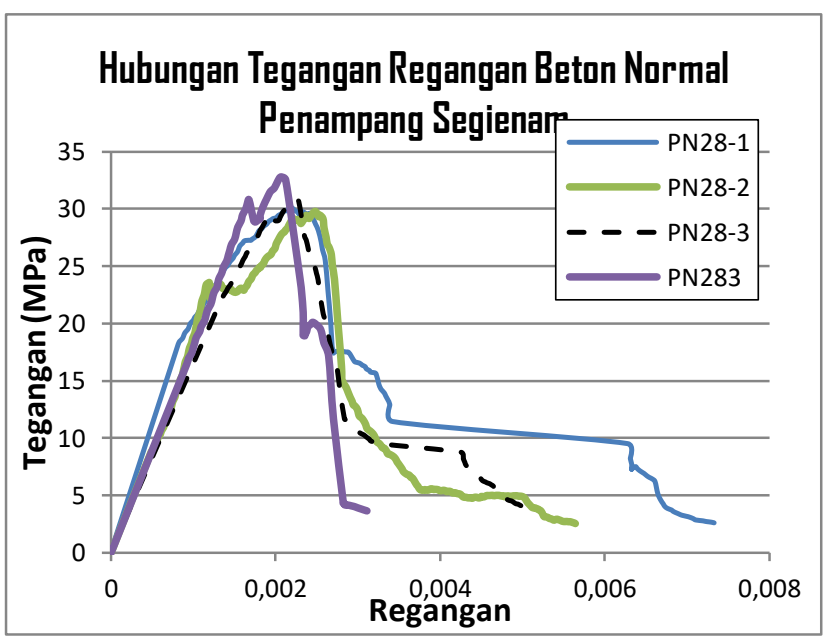

Gambar 1d

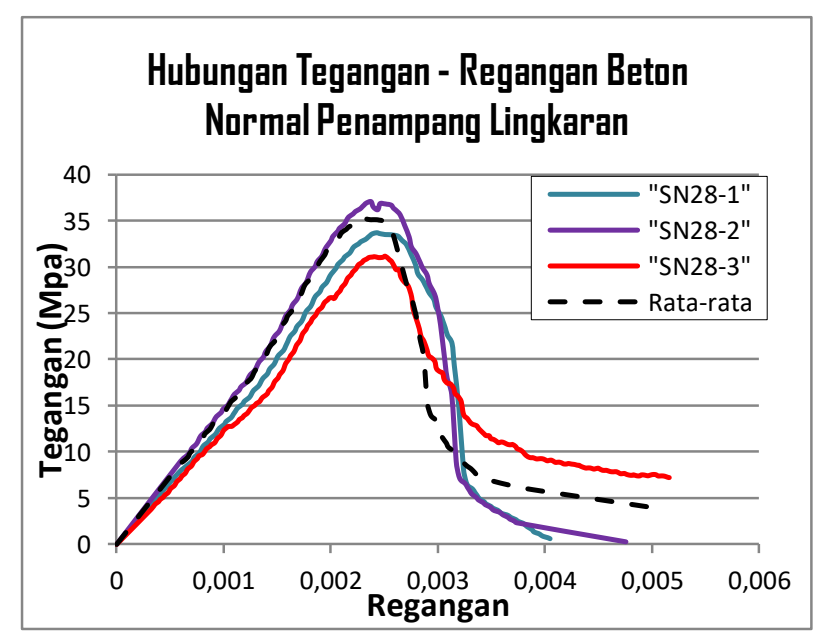

Gambar 1f

Gambar 1. Grafik Kurva Tegangan-Regangan HVFA-SCC dan Beton Normal 
Berdasarkan hasil pengujian tekan yang disajikan pada gambar 1a-1f didapatkan bahwa beton normal memiliki kekuatan lebih besar dibandingkan dengan HVFA SCC dengan rata-rata penurunan sebesar $27 \%$. Bentuk penampang yang memiliki kekuatan terendah untuk beton normal dan HVFA SCC adalah beton dengan penampang segi empat dengan rata-rata kenaikan sebesar $23 \%$ untuk segienam dan $41 \%$ untuk lingkaran.

Pembahasan Hasil Pengujian Hubungan Tegangan-Regangan HVFA-SCC dan Beton Normal

Hasil grafik hubungan tegangan-regangan yang ditampilkan di atas untuk masing-masing bentuk spesimen kemudian dirata-rata perkenaikan beban $(\mathrm{P})$ dengan menentukan batas regangan yang akan disajikan dalam Gambar 2 dan gambar 3

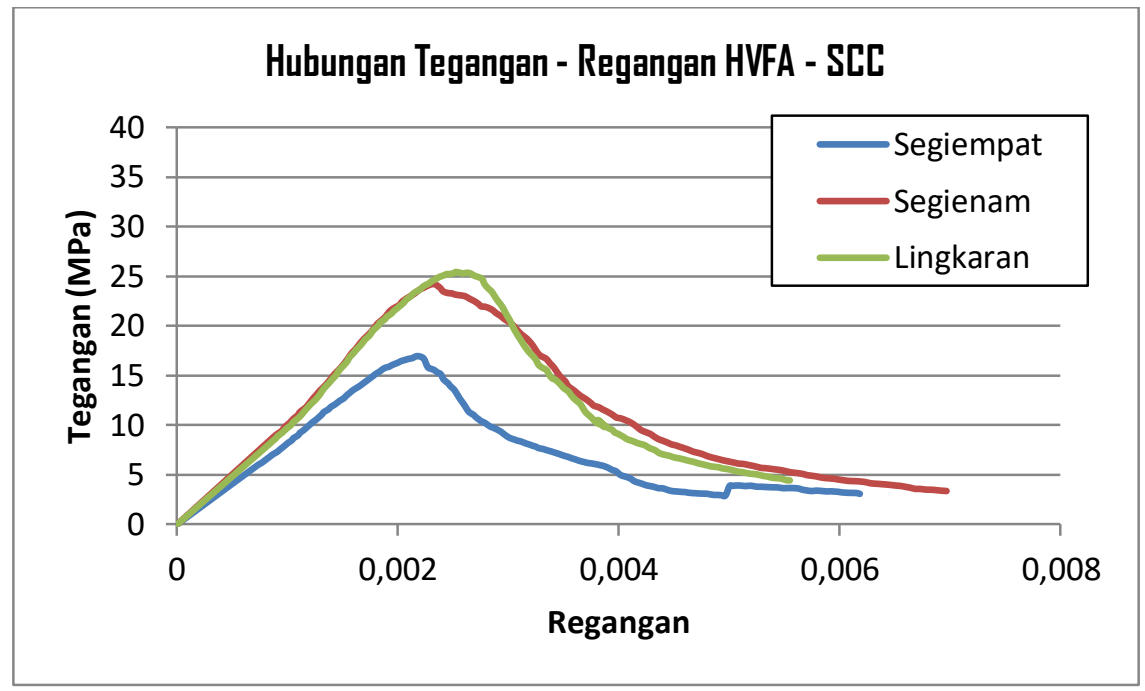

Gambar 2. Grafik Perbandingan Kurva Tegangan-Regangan HVFA-SCC

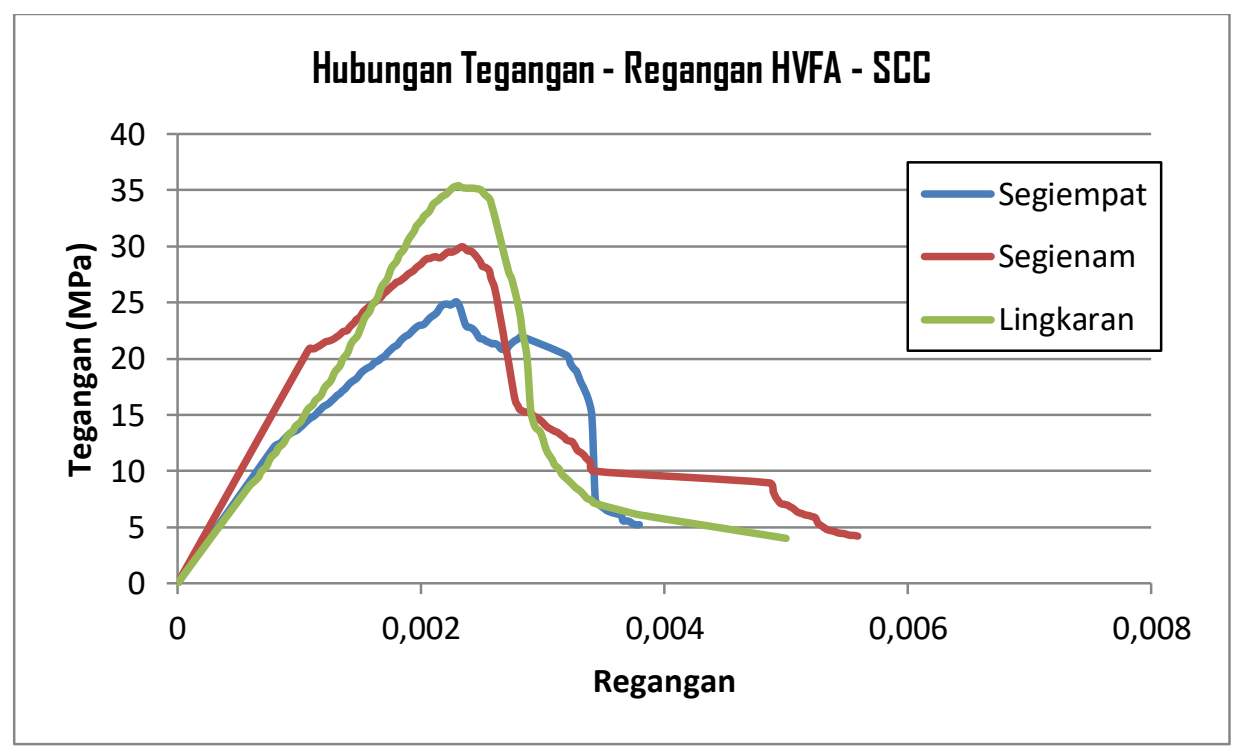

Gambar 3 Grafik Perbandingan Kurva Tegangan-Regangan Beton Normal 
Berdasarkan Gambar 2 dan 3 dapat dilihat bahwa bentuk penampang mempengaruhi kekuatan dan postpeak beton dan terlihat bahwa bentuk penampang yang tidak memiliki sudut memiliki kuat tekan yang lebih besar. Untuk beton normal (gambar 3) dengan penampang lingkaran, terjadi penurunan yang signifikan pasca puncak, sedangkan untuk penapang segiempat dan segienam menunjukkan softening yang tidak begitu tajam. Pada HVFA-SCC, perilaku post-peak pada semua sampel hampir sama, turun secara signifikan namun lebih landai dibandingkan dengan beton normal, dan secara umum semua sampel HVFA-SCC memiliki perilaku post-peak lebih landai dibandingkan dengan beton normal

Berdasarkan grafik di atas didapatkan beberapa data dari setiap variasi sampe yang disajikan dalam tabel 3 Tabel 3 Data Hasil Uji HVFA-SCC

\begin{tabular}{llccc}
\hline \multirow{2}{*}{ No } & \multicolumn{1}{c}{ Parameter } & \multicolumn{3}{c}{ Bentuk Penampang } \\
\cline { 3 - 5 } & & Segiempat & Segienam & Lingkaran \\
\hline 1. & Maximum stress $\left(f^{\prime} c\right)(\mathrm{MPa})$ & 16,94 & 24,25 & 25,4 \\
\hline 2. & Peak strain $\left(\varepsilon_{0}\right)$ & 0,0022 & 0,0023 & 0,0025 \\
\hline 3. & Maximum strain $\left(\varepsilon_{\text {max }}\right)$ & 0,0069 & 0,0063 & 0,006 \\
\hline 4. & Modulus Elastisitas $(\mathrm{Ec})(\mathrm{MPa})$ & 9378,2 & 9656,33 & 9700,89 \\
\hline
\end{tabular}

Tabel 4 Data Hasil Uji Beton Normal

\begin{tabular}{|c|c|c|c|c|}
\hline \multirow{2}{*}{ No } & \multirow{2}{*}{ Parameter } & \multicolumn{3}{|c|}{ Bentuk Penampang } \\
\hline & & Segiempat & Segienam & Lingkaran \\
\hline 1. & Maximum stress $\left(f^{\prime} c\right)(\mathrm{MPa})$ & 25,04 & 30,89 & 35.38 \\
\hline 2. & Peak strain $\left(\varepsilon_{0}\right)$ & 0,0023 & 0,0023 & 0,0024 \\
\hline 3. & Maximum strain $\left(\varepsilon_{\max }\right)$ & 0,0057 & 0,0052 & 0,0051 \\
\hline 4. & $\begin{array}{lll}\text { Modulus } & \text { Elastisitas } & (\mathrm{Ec}) \\
(\mathrm{MPa}) & \end{array}$ & 12313,54 & 14335,10 & 14674,68 \\
\hline
\end{tabular}

Berdasarkan hasil pengujian di atas didapat bahwa perbedaan bentuk penampang pada sampel beton normal maupun HVFA-SCC berpengaruh pada kekuatan beton. Beton dengan bentuk penampang lingkaran memiliki kuat tekan lebih besar daripada beton yang penampangnya memiliki sudut. Hal ini disebabkan pada bentuk penampang lingkaran beban yang datang disebarkan secara merata pada setiap titik pada lingkaran, sedangkan pada beton yang penampangnya memiliki sudut, pada setiap titik penampangnya menerima beban yang berbeda-beda. Pada Tabel 3 dan Tabel 4 dapat dilihat pula pada umur yang sama 28 hari, kekuatan beton normal lebih tinggi dibandingkan dengan HVFA-SCC.

Berdasarkan grafik hasil pengujian diatas didapat bahwa beton dengan bentuk penampang persegi memiliki nilai regangan lebih besar daripada beton yang berpenampang lingakaran. Hal ini menunjukkan bahwa kemampuan bertahan pasca runtuh beton berpenampang persegi lebih besar dibandingkan dengan beton berpenampang lingkaran. Selain itu didapatkan bahwa HVFA-SCC memiliki regangan maksimum yang lebih besar dibandingkan dengan beton normal. Hal ini menunjukan bahwa HVFA-SCC lebih daktail dibanding beton normal.

Berdasarkan hasil pengujian pada sampel beton 28 hari diatas terlihat bahwa Modulus Elastisitas semakin menurun pada bentuk penampang yang memiliki sudut, semakin sedikit sudutnya maka semakin kecil pula modulus elastisitasnya.Selain itu didapatkan bahwa modulus elastisitas beton normal lebih besar dibandingkan HVFA-SCC, berarti kemampuan beton normal dalam menahan tegangan aksial dengan regangan sekecil mungkin lebih besar dibanding HVFA-SCC. 
Selain nilai-nilai diatas, Gambar 3 dan Gambar 4 juga dapat digunakan untuk menghitung nilai toughness yaitu dengan mencari daerah dibawah gambar 3 dan gambar 4 . Nilai toughness merupakan energi yang diserap oleh sebuah elemen pada saat pembebanan, dimana hal ini menunjukan seberapa besar kemampuan sebuah elemen untuk menyebarkan secara merata energi yang diterimanya akibat pembebanan. Berikut adalah hasil nilai toughness yang ditampilkan pada Tabel 5.

Tabel 5 Data Hasil Penghitungan Toughness

\section{Toughness}

No Jenis Sampel

\section{Pre-Peak Post-Peak Total}

\begin{tabular}{lllll}
\hline 1 & Beton Normal (Prisma Segiempat) & 0,033 & 0,035 & 0,068 \\
\hline 2 & HVFA - SCC (Prisma Segiempat) & 0,019 & 0,027 & 0,047 \\
\hline 3 & Beton Normal (Prisma Segienam) & 0,041 & 0,031 & 0,071 \\
\hline 4 & HVFA - SCC (Prisma Segienam) & 0,029 & 0,045 & 0,074 \\
\hline 5 & Beton Normal (Silinder) & 0,041 & 0,033 & 0,073 \\
\hline 6 & HVFA - SCC (Silinder) & 0,033 & 0,037 & 0,070
\end{tabular}

Berdasarkan hasil perhitungan didapatkan bahwa nilai toughness pascapeak dari HVFA-SCC lebih besar dibandingkan nilai toughness pascapeak beton normal. Dengan kata lain kemampuan HVFA-SCC untuk menyebarkan secara merata energi yang diterimanya akibat pembebanan pada saat post peak lebih besar dibandingkan dengan kemampuan beton normal pada saat yang sama.

Gambar 2 dan Gambar 3 juga dapat digunakan untuk menghitung nilai daktilitas. Peneliti menggunakan perbandingan antara regangan maksimal dibanding dengan regangan saat $0,4 \mathrm{f} \mathrm{c}$ unutk menghitungan nilai daktilitas. Berikut adalah hasil nilai daktilitas yang ditampilkan pada Table 6 .

Tabel 6 Data Hasil Uji Daktilitas dengan Metode Perbandingan Regangan

\begin{tabular}{llccc}
\hline \multirow{2}{*}{ No } & Jenis Sampel & $\begin{array}{c}\text { Regangan } \\
\text { Maksimal } \\
\end{array}$ & $\begin{array}{c}\text { Regangan } \\
\text { Saat } \mathbf{0 , 4} \mathbf{F}^{\mathbf{}} \mathbf{c}\end{array}$ & Daktilitas \\
\hline \multirow{2}{*}{1} & Beton Normal (Prisma Segiempat) & 5,2 & $\mathbf{( 1 0 ^ { - 3 } )}$ & \\
\hline 2 & HVFA - SCC (Prisma Segiempat) & 6,3 & 0,79 & 6,57 \\
\hline 3 & Beton Normal (Prisma Segienam) & 5,7 & 1,29 & 6,43 \\
\hline 4 & HVFA - SCC (Prisma Segienam) & 6,9 & 0,81 & 8,46 \\
\hline 5 & Beton Normal (Silinder) & 5,1 & 0,97 & 5,28 \\
\hline 6 & HVFA - SCC (Silinder) & 6,0 & 1,03 & 5,89 \\
\hline
\end{tabular}


Berdasarkan perhitungan daktilitas diatas didapatkan bahwa pada sampel HVFA-SCC nilai daktilitasnya lebih tinggi dibandingkan dengan Beton Normal. Hal ini menunjukkan bahwa kemampuan bertahan HVFA-SCC hingga ambang keruntuhan lebih tinggi dibanding dengan beton normal.

\section{Kesimpulan}

Berdasarkan hasil analisa dan pembahasan di atas dapat disimpulkan bahwa :

a. HVFA SCC pada umur 28 hari memiliki kuat desak yang lebih rendah dibandingkan dengan beton normal dengan rata rata penurunan kekuatannya adalah $27 \%$.

b. Beton normal dengan penampang segiempat memiliki kuat desak terendah dengan kenaikan sebesar $23 \%$ untuk segienam dan $41 \%$ untuk lingkaran, begitupula dengan HVFA-SCC, penampang segiempat memiliki kuat desak terendah dengan kenaikan sebesar 43\% untuk segienam dan 52\% untuk lingkaran.

c. Nilai Modulus Elastisitas rata-rata pada HVFA-SCC lebih kecil dibandingkan beton normal, yaitu 9578,47 MPa untuk HVFA-SCC dan 13774,44 MPa untuk beton normal.

d. Nilai toughness postcapeak rata-rata dari HVFA-SCC lebih besar dibandingkan nilai toughness postcapeak beton normal, yaitu 0,036 untuk HVFA-SCC dan 0,033 untuk beton normal.

e. Nilai daktilitas rata-rata HVFA-SCC lebih tinggi dibandingkan dengan Beton Normal, yaitu 6,93 untuk HVFA-SCC dan 5,44 untuk beton normal.

\section{Daftar Pustaka}

Anonim. 2000. "SNI 03-1974-1990, "Metode pengujian kuat tekan beton”. Badan Standarisasi Nasional, Jakarta.

Desi, Candra, Flexural Behavior of Reinforced Concrete Beams Type High Volume Fly Ash-Self Compacting Concrete (HVFA-SCC); Surakarta : Sebelas Maret of University ; 2016

Elwet, D. J., \& Fu, G. (1995). Compression Testing of Concrete: Cylinders vs. Cubes. New York: New York State Department of Transportation.

J.R. del Viso, dkk.2007." Shape and size effects on the compressive strength of high-strength concrete", Universidad de Castilla-La Mancha, 13071 Ciudad Real, Spanyol

Neville, A. M. (2002). Properties of concrete. John Wiley \& Sons.

Park, R. and Paulay T. (1974). Reinforced Concrete Structure. New York: Wiley Interscience Publication

Septian, Dedi. 2011."Pengaruh Kadar Fly Ash Sebagai Pengganti Sebagian Semen Terhadap Modulus Elastisitas Pada High Volume FlyAsh-Self Compacting Concrete. Universitas Sebelas Maret, Surakarta.

Siddique R.2004. "Performance characteristics of high-volume Class F fly ash concrete". Cement and Concrete Research, 34, hal 487-493. 